change in the circumference of finger joints has become a standard method of assessment in rheumatology trials; yet it depends on selection of the right type of patient if it is to be effective.5 A different kind of misuse of randomised clinical trials is that they have become part of promotional campaigns; there is now a huge literature comparing antirheumatic drugs with each other. Yet papers can easily be selected to show that the effect of a drug $A$ is greater than drug $B$, which is greater than drug $C$, which is greater than drug A: such an Escher spiral must have required considerable effort by clinicians, but whose interests have been served?

So Cranberg's argument that retrospective controls may be valid is worth considering. Until recently this might have meant reliance on the memory of subjective evidence; but data are now collected in more objective form and, as Cranberg says, are more easily retrieved. To be sure, strictures about methods and their use in randomised controlled trials apply just as forcibly to the use of historical controls, but they do not sway the evidence in favour of the randomised trial. An argument often advanced against comparisons based on retrospective data is that patterns of disease change. But how rapid are such changes in relation to the periods concerned? And if change is rapid, perhaps for environmental reasons, then a randomised trial may be invalidated just as much as any other.

In his wide-ranging paper that includes comments on randomised controlled trials Black concludes that "in spite of these reservations, I would agree that if a controlled trial is practicable and can produce a result, it is a most valuable contribution to progress...." That and no more: the controlled trial has been placed on too high a pedestal and needs to be brought back to earth.

${ }^{1}$ Popper, K, Unended Quest: an Intellectual Autobiography. Fontana/ Collins, 1976.

2 Black, D, fournal of the Royal College of Physicians of London, 1979, $13,57$.

${ }^{3}$ Dollery, C T, fournal of the Royal College of Physicians of London, 1977, 11, 226.

${ }^{4}$ Empire Research Council, Annals of the Rheumatic Diseases, 1961, 20, 315.

${ }^{5}$ Hart, F D, and Huskisson, E C, Lancet, 1972, 1, 28.

\section{Who carries the can?}

Clinical medicine, and especially therapeutics, advances by a process of evolution, in which only the changes proved to be of value survive. New ideas and new drugs are introduced and assessed and either accepted into the body of orthodox medicine or rejected. In recent years, for example, betablockers and bypass grafting have become accepted treatments for coronary heart disease, while anticoagulants and hyperbaric oxygen have fallen into disfavour.

Unfortunately these evolutionary principles do not seem to be applied to changes in the organisation of medicine. Only rarely is any attempt made at a pilot study: more often a committee makes its report and new measures are introduced with no built-in system for their evaluation. An innovation may be introduced with all the fervour of a divine revelation - but the conviction of enthusiasts is a poor substitute for objective evidence based on scundly constructed experiments. More important, when practical experience suggests that an innovation does not work there is no mechanism for it to fade silently away.
So the disenchantment evident in Appleyard and Maden's criticism of multidisciplinary teams ( $p$ 1305) is not really surprising. These teams were introduced into clinical medicine as part of a new gospel-consensus management-which was envisaged as a bright new solution to some of the discontents in the Health Service. No doubt there are circumstances in which consensus management does work, but making clinical decisions is not one of them. As the authors explain, the fundamental defect in the concept of team management is that individuals will follow decisions with which they disagree only if they are forced to do so. If the team is arranged in the old-fashioned hierarchical fashion, with the doctor as boss, he can enforce such decisions; but in the current set-up a social worker or psychologist who disagrees with the team decision remains free to obstruct it by refusing, for example, to arrange for special education for a disturbed child. Neither the legal nor the ethical implications of obstruction of this kind have yet received enough attention.

Whatever the defects of the old system, in which the doctor was an autocrat who took advice from his colleagues but then made his own decision, it had two important merits. Firstly, the patient knew who was treating him. All too often nowadays patients are made confused and miserable by obvious conflicts and anomalies in their treatment by different health professionals. Secondly, when things went wrong, the doctor carried the can-and at worst had to appear in court and possibly pay damages or answer charges before the General Medical Council. Few of the new health professions have established procedures (comparable to those for doctors and nurses) for dealing with unprofessional or unethical conduct by their members. And where does the legal responsibility lie in these days of team management? The recent spate of civil liability cases in which damages have been awarded against health authorities suggests that they will be held liable for errors and omissions made by the teams they employ-but spreading responsibility so widely must encourage individuals to believe that they were not to blame. In traditional clinical medicine doctors (most often) learnt from their mistakes: the new-style medicine of modern management seems to be designed in such a way that no one has to admit that the mistake may have been his or her fault.

\section{Asymptomatic complete heart block}

The widespread practice of recording routine electrocardiograms in almost every patient attending the medical outpatient department has led to general physicians seeing many more asymptomatic patients with complete atrioventricular block. In these circumstances the risk of syncope in individual patients is unknown; but some clinicians have taken the view that it is always sufficient to warrant prophylactic insertion of a pacemaker.

Atrioventricular block may be due to lesions at any of three sites: the atrioventricular node, the bundle of $\mathrm{His}$, or the bundle branches. ${ }^{1}$ Structural abnormalities affecting the His-Purkinje system are generally believed to be progressive, so that Adams-Stokes attacks are more likely to develop in such cases; in contrast, abnormalities affecting the atrioventricular node have a more benign course. ${ }^{2}$ The introduction of His bundle electrography has allowed cardiologists to define 